\title{
Vivienda vernácula de las provincias de Cusco
}

\author{
Vernacular housing of the provinces of Cusco
}

ORCID: 0000-0001-7532-2993

\section{RESUMEN}

La vivienda vernácula es la representación de la tradición, cultura y propia tecnología desarrollada por sus habitantes, respetando su entorno físico y cultural, así como el empleo de materiales de la zona y técnicas ancestrales. Este tipo de arquitectura es poco estudiada y mucho menos documentada. En el caso cusqueño, que posee muchas muestras de esta tipología tradicional, necesita ser expuesta y analizada; por lo que el objetivo del presente estudio radicó en la exploración y análisis arquitectónico de dichas edificaciones. La metodología aplicada respondió al método de investigación general de las ciencias sociales, apoyándose en la exploración; cada expresión arquitectónica analizada presenta particularidades individuales y coincidencias entre ellas. Las edificaciones analizadas mostraron diferencias sustanciales en los materiales y técnicas constructivas utilizadas, respondiendo a procesos culturales y materiales de su entorno; sin embargo, también presentan coincidencias en aspectos de distribución formal, poseyendo espacios centrales que no solo cumplen con la función de distribución de ambientes, sino que se convierten en los espacios fundamentales de la edificación, donde se desarrollan las actividades sociales, laborales y alimenticias.

Palabras clave: Arquitectos, clima, entorno, materiales, técnica.

\begin{abstract}
The vernacular housing is the representation of the tradition, culture and own technology developed by its inhabitants, respecting their physical and cultural environment, as well as the use of materials of the area and ancestral techniques. This kind of architecture is little studied and much less documented. In the case of Cusco, which has many samples of this traditional typology, it needs to be exhibited and analyzed; therefore, the objective of this study was to explore and analyze the architecture of these buildings. The methodology applied responded to the general research method of social sciences, based on exploration; each architectural expression analyzed presents individual peculiarities and coincidences among them. The buildings analyzed showed substantial differences in the materials and constructive techniques used, responding to cultural and material procedures of their environment; however, they also present similarities in aspects of formal distribution, possessing central spaces that not only fulfill the function of distribution of environments, but also become the fundamental spaces of the construction, where social, labor and food activities are developed.
\end{abstract}

Keywords: Architects, climate, environment, materials, technique.

${ }^{1}$ Universidad Andina del Cusco. Escuela Profesional de Arquitectura. Cusco, Perú. E-mail: cvargasfebres@hotmail.com 


\section{INTRODUCCIÓN}

El origen del término "arquitectura vernacular", según Guerrero (2010), lo estableció William Gilpin en 1748 publicando el libro Un diálogo sobre los jardines, donde se hace la primera defensa de la arquitectura tradicional, con la peculiaridad de ser edificada por sus propios habitantes. Dicho texto tuvo por objetivo la definición tipológica de origen nacionalista a nivel global. Dando mayor alcance, Vasquez, Navarrete \& Castillo (2018) afirman que el patrimonio tradicional o vernáculo construido se encuentra en peligro de desaparición.

Rapoport (1972), como exponente con mayor autoridad para hablar sobre arquitectura vernácula, considera que la arquitectura vernácula es generada por un fenómeno cultural; es el producto de transformaciones sociales con grandes componentes religiosos y funcionales que permiten la integridad espacial en convivencia con el entorno y la forma de vivir de su comunidad. Además, para Peñaranda (2011), la percepción de peligro a la extinción de esta arquitectura tradicional es que los habitantes que residen en espacios contemporáneos consideran a estas viviendas tradicionales como ausentes de seguridad, salubridad y las vinculan con espacios de pobreza, sin reconocer los valores que existen en la vivienda, fruto del legado cultural y producto de soluciones coherentes a exigencias determinadas.

La evolución del interés por la arquitectura vernácula nace a partir de la década de los 50 con el interés de algunos arquitectos por el tema. Ya en 1964 en el Museo de Arte Moderno de Nueva York en una exposición dedicada a edificaciones tradicionales, se propuso denominarlas como bellas artes. Estudios mucho más serios se dieron a partir de 1976 con la formación en ICOMOS del comité especial para la promoción de la cooperación internacional, para el reconocimiento y la custodia de la arquitectura vernacular. El interés más alto se dio en 1997 con la presentación de Paul Oliver de su publicación denominada Enciclopedia de
Arquitectura Vernacular del mundo, dicho trabajo a la fecha representa el mayor acercamiento y profundización del tema en cuestión(Chaos, 2015).

ICOMOS (1999) recomienda, dentro de su política sobre la arquitectura vernácula, la implementación de programas informativos que coadyuven la conciencia grupal de la cultura autóctona para el conocimiento de las nuevas generaciones.

Para Tilleria (2010), a pesar de que distintas sociedades cuentan con similitudes en los ámbitos sociales, culturales y de territorio, siempre se generarán singulares resultados fijados por las interpretaciones de cada individuo, la arquitectura popular no representa la misma solución para los mismos problemas, sino que concede siempre un margen para sus propias y distintivas decisiones. En el mismo sentido define:

Lo patrimonial: Considerando que la cultura no solo se registra en los monumentos, sino también en la escala de lo doméstico. En 1964, con la carta de Venecia, lo patrimonial incorpora temas de ruralidad; en 1972, la carta de Paris define al "patrimonio natural" y "cultural"; en 1975, la Carta de Amsterdam incluye el interés por las edificaciones concernientes a la arquitectura vernácula y de carácter preindustrial. En 1976, la carta de Nairobi refiere al "conjunto tradicional" entendiendo como valor patrimonial a la vida tradicional de un pueblo. En 1999, ICOMOS señala a la importancia de esta arquitectura como expresión de identidad en lo descrito en la Carta del Patrimonio Vernáculo Construido.

Evocador de memoria: De acuerdo a lo citado por Tilleria: Ruski, en su libro Las siete lámparas de la arquitectura, alude que la arquitectura es el contenedor de las memorias colectivas, siendo así la arquitectura popular la más ligada a esta definición, la memoria habita en las características de esta, desde los materiales hasta los sistemas constructivos. 
Los arquetipos: Son variados los componentes que generan la imposible categorización de los tipos de esta arquitectura, cada resultado es único y diferente. Los resultados se encuentran designados por las posibilidades constructivas de los materiales, geometría, clima.

De igual forma CIAV-ICOMOS (1993) determina las características de la arquitectura vernácula:

- Empleo de conocimiento tradicional, común, no académico, desde su diseño hasta su edificación.

- Existencia de procesos constructivos acoplados por los integrantes de comunidades específicas.

- Transformación de la prolongación de la cultura vernácula.

- Empleo de técnicas antiguas, costumbristas y artísticas.

- Empleo de materiales propios del lugar como la tierra, madera, piedra, etc.

- Capacidad de adecuación a actuales coyunturas y exigencias temporales.

- Atención a lo morfológico, tipológico, compositivo, escala, plasticidad, volumétrico, entorno y edificación de conjunto.

La arquitectura vernácula suele ser relacionada con lo primitivo, con lo pobre y básico, por ende, se vuelve un concepto negativo en lo que se refiere a arquitectura. La palabra vernáculo proviene del término en latín vernaculus que significa "doméstico, nativo de casa o país propio". El término de arquitectura vernácula se refiere a la concepción de una arquitectura proveniente de un individuo, sin ser especializado como lo sería el arquitecto. En la arquitectura vernácula, los recursos utilizados son de origen regional, y de manera tradicional, evitando así el abuso o explotación de estos.

"Cada uno de los lugares expresa con claridad las peculiaridades de su mundo cercano. En ellas encontramos arquitecturas que son producto del ánimo positivo de sus realizaciones $y$ el fruto que responde básicamente a tres cuestiones: necesidad, lugar y construcción. Una cueva excavada en la montaña o la cubrición de una estructura para secar tabaco... cada caso registra su forma de proceder, el resultado de aplicar una estrategia, casi siempre escasa en recursos. Aqui la precariedad, lejos de ser una rémora para la arquitectura, suele serle de ayuda. Las limitaciones son convertidas en situaciones favorables."... (Jimenez, 2006).

Por otro lado, según Chaos (2015), la arquitectura contemporánea se aleja de sus orígenes, dejando de lado temas tan importantes como la adaptación al medio, el trayecto del sol, el empleo de materiales y las técnicas constructivas locales. Todo ello da como resultado el encarecimiento de presupuestos de la obra, por la importación de materiales escogidos, ingentes recursos no renovables; todos ellos relacionados con los procesos edificatorios. Por ello, la tecnología contemporánea es acusada de ser la autora del olvido de nuestro origen. La antes sólida relación del hombre con la naturaleza es ahora un creciente abismo provocado por la creciente creación de materiales y sistemas industrializados.

Por su parte, Gómez (2010) define a lo vernáculo como arquitectura efímera urbana, exponiendo que para la categorización de los edificios como arquitectura efímera urbana debe de cumplir con dos características esenciales: la utilización de materiales de construcción no duraderos y localizarse en un sitio ajeno. Sin embargo, existe una tercera característica: el carácter urbano de la construcción. Esto significa que la condición urbana de un edificio se alude a su filiación a una ciudad, dejando de lado el ámbito legal, esto excluye primordialmente a las edificaciones construidas en zonas rurales que generalmente no dependen directamente de una ciudad. Acorde a lo citado por Gómez (2010), en Inglaterra, la desaparición de edificios comunes a causa de la revolución industrial así como en Estados Unidos con su gran pérdida de edificios "comunes" se generó 
un interés por la arquitectura vernácula en la revolución cultural.

Uno de los requisitos que generalmente se asocia a la arquitectura vernácula es la materialidad de esta, su uso es primordial para poder señalar si una edificación es vernácula o no. Paul Oliver sustenta que se considera vernáculo a la arquitectura de las personas, construida por estos mismos, usando materiales de la localidad y tecnologías tradicionales (Araoz, 1995).

En otro sentido, Paniagua Padilla (s/f) señala que la arquitectura vernácula se la reconoce tomando en cuenta los diferentes climas en los que se ubica, así; establece sectores climáticos:

Clima Cálido (Costa) - Seco de latitudes bajas: Se caracteriza por la alta incidencia de radiaciones solares en periodos de las mañanas, y las noches. El fenómeno de re irradiación por las noches es potente, observando una clara disminución de la temperatura al momento de la puesta de sol. De aquí desemboca en una oleada térmica bajo extremos que no llegan al confort térmico adecuado. De igual forma, establece el constructo de "invariables" como elemento denominador de las diferentes edificaciones que puedan catalogarse como vernáculas de este tipo de clima.

- Protección de la radiación solar

- Construcciones pesadas generando masa térmica

- Enfriamiento evaporativo

- Enfriamiento radiante.

Clima cálido (Selva) - Húmedo de latitudes bajas: Se caracteriza por el alto porcentaje de humedad, la pérdida de claridad atmosférica causada por la humedad concentrada en el aire, así como la nubosidad, por lo que impide el paso de la radiación solar produciendo menores irradiancias superficiales. Sus invariantes reconocidas son la defensa de la radiación solar, así como la infraestructura ventilada.
Clima templado de latitudes medias: Situadas entre los $20^{\circ}$ y $60^{\circ}$, varía en los meses de verano con alturas solares máximas, así como en épocas de invierno, dichas alturas se reducen produciendo dos estaciones térmicas muy diferenciadas, se observa presencia de vientos polares.

Clima frío de latitudes altas y climas de montaña: Escasa presencia de radiación solar debido a la alta presencia de masa atmosférica. Se caracteriza que pese a estar en verano, las temperaturas presentes son muy bajas, mientras que la radiación solar baja que presenta impide plantear estrategias de captación. Debido a la alta humedad produce la sensación térmica fría. Sus invariantes son el aislamiento térmico y conservación de la energía, materiales de acabados en el interior con calentamiento lento, ventilación que elimina el exceso de humedad.

Para Landa \& Segura (2017), se tiene que recalcar que la arquitectura vernácula no solo se encuentra en las locaciones rurales, ya que muchas veces se tiende a usar este tipo de arquitectura en otros ajenos al de su origen. Otro de los padecimientos es el mal entendimiento que se tiene de lo vernáculo. Cuando se realizan remodelaciones donde todos los interiores son cambiados, genera que la arquitectura empleada sea vista de tradicional, conservando las fachadas para la escenografía rural. De los mismos autores se desprende que después de mencionar todos estos puntos se da a conocer que la arquitectura vernácula es muchas veces tratada de una forma errónea, ya que se toma en cuenta lo rural, viéndolo necesariamente ligado a la pobreza, por ende, el intentar recrearla trae una idea falsa o incompleta de lo que realmente se caracteriza.

\footnotetext{
Algunas definiciones conceptuales

Antes de definir a la arquitectura vernácula, se debe realizar un deslinde conceptual para no confundirla entre términos o definiciones de constructos como arquitectura popular, bioclimática, sostenible o doméstica.
} 
La sostenibilidad proviene desde las ciencias biológicas y responde a la armonía entre una especie y los recursos de su medio. El menoscabo de los presentes recursos conduce a la extinción de la especie, además que los agentes como el cambio climático o modificaciones del entorno favorecen a la disminución de dichos servicios y bienes. Para la arquitectura, los recursos en peligro son el agua, materiales de edificación y la energía (Neila, 2015).

Del mismo autor se desprende que la arquitectura popular se origina en el pueblo (popularis); se encuentra ligada a la tradición y costumbre de los pueblos. Es una arquitectura modesta, no posee lineamientos esenciales ni la participación de técnicos en la elaboración de sus planos, siguen reglas no escritas.

La arquitectura vernácula se origina en lo vernáculas, (doméstico), se vincula al lugar donde se ubica, se caracteriza porque al momento de proyectar se fija en las condiciones climatológicas, y de la mano de su historia, sus costumbres, la antropología que la caracteriza, así como los medios de producción de su ámbito. La arquitectura tradicional se define como la que se edifica con técnicas constructivas y formas más específicas que la arquitectura popular, distinguiéndose por el empleo de materiales tradicionales y no contemporáneos. No se vincula con el lugar y de igual forma se distingue de edificaciones simples populares. Finalmente, el autor sentencia que todas estas definiciones se relacionan unas con otras; sin embargo, se diferencian ya que lo popular se relaciona a la tradición y con ello evoluciona con su historia gradualmente y, por otro lado, lo vernáculo se origina en la representación de la arquitectura tradicional utilizando sus experiencias. Emplea nuevos sistemas constructivos y novedosos materiales para mimetizarse en la contemporaneidad.

Para CIAV-ICOMOS (1993), la arquitectura vernácula se caracteriza por estar aislada en grupos urbanos históricos o conjuntos modernos. Es la representación de valores históricos y auténticos registrados en una sociedad, con directa relevancia con su entorno económico, físico y cultural. Se la reconoce como una arquitectura local o regional, la decisión de las formas, estructuras y materiales dependen de la geología, clima, el lugar, la cultura y su economía. Siguiendo el mismo enfoque, para ICOMOS (1999), es la manifestación esencial de la identidad de una sociedad, de sus vínculos con el territorio y la manifestación de la diversidad cultural a nivel global. Conforma la manera natural y costumbrista en que los grupos sociales han generado su propio hábitat; se caracterizada por una realidad cambiante, así como por la prolongada adaptación como solución a solicitudes sociales.

Por otro lado, Carranza (2010) define a lo vernáculo como el tipo de arquitectura que fue diseñada por los pobladores de una región o periodos históricos específicos a través del conocimiento tácito y las experiencias; dichas edificaciones se caracterizan por el uso de materiales accesibles de su entorno como la madera, el bambú, el adobe, etc.

La arquitectura vernácula labora íntimamente con el lugar de la ubicación, además con el micro clima; existe respeto por los demás pobladores y sus hogares, y por ende con su entorno integral, natural o producido por el ser humano (Rapoport, 1972). Es la que se diferencia de otras debido a que, expuestas sus formas, funcionalidad, y espacialidad, se concreta como generación directa de la reflexión de sus habitantes referido a su entorno y sus necesidades (King, s/f).

Del mismo constructo, Sepulveda (2002) define que depende de un sitio, existe desde siempre, es atemporal, y persiste ahí en la memoria colectiva. La define como una arquitectura producida por las manos que, en varios casos, analiza la utilización del espacio y la luz. Es aquella que pondera y se interna en discusiones funcionales tipológicas, la manipulación del 
material y especialmente a un tema transversal a estas culturas que es el color.

La arquitectura vernácula es el grupo de construcciones en las que se registran sistemas constructivos propios de espacios geográficos, y que son edificadas a través de materiales propios de la zona, caracterizándose por la volumetría de sus formas, colorimetría, funcionalidad, y los espacio interiores y exteriores que conforman un grupo de rasgos característicos, lo que abala la manufactura de quien la edifica (Estrada, 2005).

Así la arquitectura tradicional y popular es un fenómeno habitual que normalmente se le relaciona a diferentes procesos, se direcciona sustancialmente en la investigación de soluciones ancladas en la tradición, en el saber popular. La arquitectura vernácula es la mayor manifestación de identidad desde el origen de la modernidad, existen modelos re interpretativos de la arquitectura popular, así arquitectos como Philiph Webb y William Morris ensalzan la vivienda rural tradicional; del mismo modo, Frank Lloyd Wright, Kenzo Tange, Mario Romañach, Alvar Aalto, el mexicano Luis Barragán entre otros armonizan tradiciones propias con técnicas y lenguajes modernos (Cárdenas, 2009).

Sintetizando, para Chaos (2015), el empleo de materiales propios de la zona se relaciona directamente como factor determinante para la definición de su identidad; sin embargo, los avances tecnológicos han permitido nuevos materiales que no deben oponerse a los factores tradicionales ni impedir que la arquitectura se vincule con los valores del sitio y el uso efectivo de recursos que estén a la mano de su entorno.

Adobe: Elemento de albañilería elaborado con tierra que se humedece y deja reposar por un día, luego se mezcla con paja (ichu) y agua, siendo pisado por los pobladores de manera continúa buscando mezclar todos los elementos y expulsar el aire contenido dentro del barro de preparación. Luego se lanza a moldes (adoberas) que serán enrasadas con paja y desmoldadas de inmediato para su posterior apilado y secado al aire libre.

Carrizo: Planta de tallo delgado y altura promedio de $6 \mathrm{~m}$, material utilizado en el techado de cubiertas en el ande peruano.

Chámpa: Vocablo quechua, referido al bloque de pasto silvestre fresco, extraído con las raíces expuestas, comúnmente utilizado para áreas verdes.

Chaqlapeo: Técnica de revestimiento donde se utiliza el cuero y lana de oveja, que es sumergido en una lechada de yeso y agua que se lanza a los muros para dar textura y color a las paredes.

Enchaclado: Técnica constructiva para el cubrimiento interior de techos, cuyo procedimiento se desarrolla con el "chancado" o aplastado del carrizo que se unen unos con otros mediante clavos y alambres que sirven de soporte para la colocación de yeso.

Aymi: Vocablo quechua que denota la actividad incaica de ayuda comunal recíproca para la construcción de la vivienda o trabajos agrícolas.

Tijeral: Estructura comúnmente de madera propia del lugar, en el caso del ande peruano elaborado de palos de madera eucalipto (rollizo), conformando el triángulo de soporte para la cubierta.

Wasitukukuy: Fiesta costumbrista relacionada al techado de la vivienda, donde participan los miembros de la comunidad de manera gratuita como parte de la "Aymi".

\section{Estado del Arte}

Para Rapoport (1972), la construcción vernácula carece de influencias teóricas o estéticas, más bien trabaja con el lugar y el clima, representando la sociedad, sus casas, y dando como resultado la mayor representación del ambiente total. 
Dentro de los antecedentes investigativos encontrados observamos distintos puntos de vista referidos a la arquitectura vernácula; sin embargo, el elemento en común en todas ellas es la importancia o categorización arquitectónica referido a este tipo de arquitectura; así presentamos los siguientes:

De acuerdo con ICOMOS (1999), antes de intervenir en alguna infraestructura vernácula, es necesario realizar un análisis de la forma y estructura. Para ello, la documentación será la metodología recomendada.

Como lo hace notar Gómez (2010), en su investigación titulada Vivienda Efimera urbana ¿Arquitectura vernácula?, define a la arquitectura vernácula como diseño; así, para poder darnos una idea de lo vernáculo dentro del diseño, debate ideas brindadas por John Binckerhoff Jackson y, para situarse en un ámbito más cercano, por Alberto Saldarriaga. Quienes señalan que la arquitectura vernácula, tradicional o popular hace directa referencia al lugar, la cultura de la comunidad que lo habita, además de estar realizada por personas no entrenadas académicamente. También define la vivienda efímera urbana y su condición de arquitectura vernácula. Instituido en las definiciones de "arquitectura vernácula" referenciadas, Gómez precisa haber fijado cuatro componentes: (1) no arquitectos, (2) relación entre arquitectura y cultura, (3) relación entre arquitectura y lugar, (4) arquitectura común desdeñada por la academia.

Navarrete et al. (2018) realizaron una investigación que tuvo por objetivo identificar las características de la arquitectura vernacular de la sierra norte del Estado de Puebla, para difundir esta tipología de arquitectura. La metodología empleada se realizó a través de la revisión y análisis de fuentes documentales; además, se aplicaron entrevistas a los pobladores de la región para entender sus tradiciones y costumbres. Las dimensiones analizadas fueron la organización espacial, forma, mobiliario, cimentación, muros y cubiertas. Dicha investigación concluye en que el constructor coincide con el mismo poblador que habita la vivienda, reconociendo fuertes lazos culturales de tradición, de costumbres e identidades. También la reconoce como una arquitectura sostenible, ya que emplea materiales propios de la zona que una vez finalizados vuelven a la tierra.

Por otro lado, Scaletti (2014), con su investigación, tuvo la finalidad de crear una base de datos que abarque la mayor información posible de lo que se refiere a la arquitectura tradicional que es parte del tejido urbano de Lamas, generando fichas para cada lote, además de estudiar a fondo algunos edificios, contando con más de 900 fichas para lotes individuales, planos generales y alrededor de mil fotografías, además de esto se seleccionaron cinco construcciones residenciales que brindaron las características comunes de cada área.

El investigador y arquitecto Gabriel Arboleda señala a la arquitectura vernácula como la arquitectura hecha por constructores que se instruyeron de forma empírica, en lugar de los arquitectos. Aunque el termino se usó por primeras veces durante el siglo XIX, el concepto se popularizó bastante durante el siglo pasado (XX), cuando la arquitectura vernacular fue presentada como un elemento de gran valor cultural en libros y gran aprecio estético en exposiciones de arquitectura (Scaletti, 2014).

Empleando las palabras de Camilo José Cela (1965): "Hay pueblos que parecen enfermos crónicos, caseríos que semejan fantasmas, y aldeas (hasta ciudades) que fingen el doloroso gesto del pájaro herido que no puede volar". Junto a la llegada de la industrialización, la arquitectura popular se fue perdiendo debido a la llegada de nuevos materiales y nuevas técnicas, ajenas a las tradicionales, se importaron modelos ajenos al habitar (Tilleria, 2010).

Finalmente, durante las últimas décadas, la literatura internacional cita al estudio de la arquitectura vernácula y su contribución al 
desarrollo sustentable de las sociedades (García, Tamayo \& Cobo, 2018). La relación con la que cuenta el desarrollo sustentable es que esta arquitectura brinda soluciones económicas, socialmente aceptables y amigables al ambiente, con el objetivo de garantizar el bienestar social.

Durante los primeros años del siglo XIX, se consideraba arquitectura vernácula a la asociada a las edificaciones consideradas "típicas" de cada sociedad, estas en su mayoría eran estudiadas a través de las descripciones de viajeros, misioneros y colonizadores de la época. Sin embargo, durante el transcurso de los años pasó a ser la arquitectura de lo espontáneo y anónimo (no estaba hecha por arquitectos en sí), una arquitectura adscrita como "inferior", de retraso o estancamiento en posición a los modelos arquitectónicos de la época (García et al., 2018).

Tilleria (2010) deduce la diferencia entre lo "vernáculo y moderno". Tras la industrialización, en Inglaterra se origina el interés por el patrimonio durante el siglo XIX, el movimiento Arts and Crafts observa en lo vernáculo maneras de volver a lo artesanal. Se genera respeto por la naturaleza de los materiales, los procesos de ejecución y el rescate de los oficios. Los arquitectos Baillie Scott y Voysey se apoyaron en la casa de campo y la granja tradicional para generar su arquitectura.

Al respecto García et al. (2018) realizan el análisis de la arquitectura vernacular desde las "tipologías arquitectónicas". El estudio presentado busca entender la arquitectura como un conjunto de símbolos y formas que brindan un mensaje, que a la vez resulta de respuestas técnicas, culturales, formales y ambientales, donde todas las variaciones en los edificios son resultado de un conjunto de transformaciones consecuentes de un esquema inicial. En sus resultados exponen que según el análisis e interrelación de variables de emplazamiento se generan 5 tipologías: 1) Entorno agrícola, aislada, un bloque, un piso, un portal; 2) Entorno agrícola, aislada, un bloque, dos pisos, con portal; 3) entorno edificado, continua, un bloque, un piso, con portal; 4) entorno edificado, continua, un bloque, dos pisos, con portal; 5) entorno edificado, pareada, un bloque, dos pisos, con portal.

Otro enfoque utilizado por Araoz (1995), para estudiar la arquitectura vernacular, fue el empleado desde las artes. Comprendiendo al ser como un factor cultural, el cual no se podía reducir a aspectos formales medibles y que solo se podía entender desde su fragmentación comportamental de individuo. Así, para poder corregir una visión que ningún "experto" estaba capacitado para comprender, el pintor tuvo que obtener conocimientos de etnografía o antropología estética para así poder catalogar y analizar la arquitectura vernácula de Navarra; y así, ser más exacto y analizar a detalle el problema del contraste con los cambios evolutivos y transformaciones. Para esta difícil tarea, se tuvo que abarcar toda la geografía casi pueblo por pueblo, y tomar nota de todas partes al igual que analizar todos los modelos. También menciona que, si es que el objetivo se transforma en descubrir y mostrar la arquitectura vernacular en vez de pasearse por esta o falsificarla mutilándola, para así evidenciar su belleza y acusar su degradación, pues la interrogación metodológica se encontraría resuelta, pues no se busca métodos etnográficos, sino un método artístico.

Para Gómez (2010), la arquitectura vernácula depende mucho de las condiciones del lugar en el que se encuentra (clima, terreno, etc.), siendo la forma de la arquitectura definida por estas para su mejor adecuación; sin embargo, también esta responde a la riqueza de recursos con la que cuenta el lugar. Por lo tanto, el mismo autor sentencia que la arquitectura vernácula se define por la utilización de materiales no ajenos a la zona, se caracteriza por ser una arquitectura local, incluyendo todo desde los materiales hasta las tecnologías empleadas.

Entonces para el autor, la arquitectura vernácula debe cumplir con las siguientes condiciones: 
No arquitectos. - La arquitectura vernácula proviene de alguien que comparte las mismas raíces culturales que el usuario, sin buscar innovación o sofisticación, simplemente termina siendo el resultado de lo que aprendió mediante el proceso de observación de lo que hacían sus pares culturales.

Relación entre arquitectura y cultura. - La arquitectura vernácula se define por la utilización de materiales no ajenos a la zona, se caracteriza de ser una arquitectura local, incluyendo todo desde los materiales hasta las tecnologías empleadas.

Relación entre arquitectura y lugar. - La arquitectura vernácula depende mucho de las condiciones del lugar en el que se encuentra (clima, terreno, etc.), siendo la forma de la arquitectura definida por estas para su mejor adecuación; sin embargo, también esta responde a la riqueza de recursos con la que cuenta el lugar.

Arquitectura común desdeñada por la academia. - En 1964, Bernard Rudofsky cita: "La historia de la arquitectura, como es escrita y enseñada en occidente, nunca se ha interesado por nada más que ciertas culturas". En el caso de la cultura occidental, no se toman en cuenta los arquitectos que no "representan" los valores asumidos de una cultura, sin ser el foco de atención de la academia. En Inglaterra se fundó en 1952 el Vernacular Architecture Group (VAG) y en Norteamérica el Vernacular Architecture Forum (VAF).

De todo lo expuesto líneas arriba, podemos tener el marco teórico, conceptual y de referencias investigativas que nos permite establecer la estructura de nuestra investigación que estará situada en los límites geográficos de las regiones de Cusco y Puno, esto debido a las posibilidades de acceso al material analizado. Cabe mencionar que existe una gran diferencia de caso a caso debido a los factores culturales, geográficos y climatológicos analizados.

\section{MATERIAL Y MÉTODOS}

Antes de definir y explicar nuestro diseño metodológico, creemos necesario presentar algunas metodologías empleadas por investigadores a la hora de tratar el tema de la arquitectura vernácula.

Navarrete, Vásquez, Castillo \& Hernandez (2018) organizan las dimensiones de la variable "arquitectura vernácula" en una estructura de cinco dimensiones: organización espacial, forma, mobiliario, cimentación, muros y cubiertas:

- La organización espacial orientada a la distribución porcentual de área ocupada, cantidad y uso de ambientes, pisos construidos, coherencia de estilo, forma y apariencia referidas al contexto (materiales), distribución funcional.

- Forma: Forma geométrica de la vivienda, modulación y dimensiones del bloque, elementos constructivos como pórticos, columnas o pilares.

- Mobiliario: Materiales con los que están construidos, ubicación de los mismos, funciones que desarrollan.

- Cimentación: Materiales utilizados, tecnología empleada, profundidad.

- Muros: Materiales utilizados, sección, proceso constructivo.

- Cubiertas: Tipos de techos, materiales utilizados, elementos que lo conforman.

Por otro lado, Galindo (2013) plantea a la tipología arquitectónica como metodología adecuada para el análisis de las facciones regionales históricas, su costumbre y tradición, extraída como herramienta intuitiva del diseño arquitectónico que faculta la lectura espacial y para los conjuntos construidos. Expone textualmente "El empleo de la tipología arquitectónica busca fundamentar la construcción de los conceptos que orienten, por un lado, el estudio de obras del pasado y el presente $y$, por otro, la gestación de las nuevas costumbres". 
Además, García, Tamayo \& Cobo (2018) manifiestan que la señalización de tipologías se da desde lo individual a lo general, buscando las relaciones o características que son comunes en la edificación. De esta misma forma, la tipología de emplazamiento examina las combinaciones entre variables: tipo de entorno (agrícola o edificado), tipo de implantación (continua, aislada o pareada), número de bloques, número de pisos, presencia de portales.

A todo lo expuesto, en nuestra investigación, adoptamos la metodología propuesta por Chaos, en la que utiliza el método de investigación general de las ciencias sociales apoyándose en la exploración empírica. Mezcla componentes técnicos característicos de la arquitectura y ciencias sociales para pensar al ser humano como sujeto creador de su cultura particular. Se presenta una interrelación de variables arquitectónicas con alguna sociales conformantes del espacio.

Por tanto, los resultados expuestos en la presente investigación responden a un análisis cualitativo de la revisión fotográfica, fichas de registro y de observación levantada en campo en cada uno de los lugares específicos de las regiones de Cusco y Puno. Esto debido al acceso de la información que se obtiene de las diferentes edificaciones planteadas.

\section{RESULTADOS}

La presentación de los resultados se enfoca en mostrar las características tipológicas de los casos de estudio encontrados en las provincias de Cusco, haciendo énfasis en viviendas en actual uso y ocupación, así como el análisis funcional de las mismas.

Del muestreo establecido, se analizaron cinco casos representativos según su clima, entorno, materiales constructivos y técnicas tradicionales de edificación. De las 13 provincias del departamento se categorizaron en zonas de puna, ceja de selva, piso de valle y zona andina. Así, cada sector analizado es representativo de la tipología de vivienda vernácula cusqueña.

\section{Caso 01: Vivienda en el distrito de Colcha, provincia de Paruro, departamento de Cusco}

Desde el punto de vista del material, la vivienda tiene características propias del lugar, ya que está edificada con bloques de adobe (tierra, barro y paja) propios de la zona, así como material pétreo que se encuentra en abundancia por estar cercano al lecho del río Apurímac que atraviesa el distrito de Colcha. Por otro lado, los muros presentan acabados en embarre coloreado con arcillas de su entorno; posee algunas características especiales, ya que su ingreso lo define una bóveda de arco de medio punto con la peculiaridad de no tener clave, tan solo las dovelas de adobe distribuyen los esfuerzos a un sobrecimiento de piedra con mampostería de barro (pirka), al igual que las escaleras de acceso al segundo nivel con la misma mampostería; mientras que el entrepiso se edifica con una base de torta de barro con cañas (carrizo) que descansan sobre los durmientes de palo rollizo de eucalipto abundante en la zona. Funcionalmente, la edificación posee comunicación del exterior al interior, a través del zaguán, que deriva en un espacio central que, sin llegar a ser área edificada, representa el espacio de distribución y núcleo de las principales actividades de sus habitantes (sociales, comerciales y culturales).

\section{Caso 02: Vivienda rural en el distrito de Ocongate, provincia de Quispicanchis, departamento de Cusco}

Si la arquitectura vernácula se caracteriza por su compromiso y simbiosis con su entorno y materiales, este ejemplo grafica de mejor manera todo lo que en la teoría antes expuesta se intenta deducir. La vivienda tradicional en el distrito de Ocongate, pese a no ser una vivienda de pastoreo, es una edificación aislada del núcleo urbano; básicamente obedece a las actividades de cultivo de altura que realiza la familia, se compone de un solo ambiente rectangular en la que al interior se subdivide por elementos virtuales como ropa, paja u otro que permita subdividirlo. Cumple con las cuatro 
características expuestas por Sepúlveda ya que los muros están edificados por bloques de pasto silvestre comúnmente llamados "Champá”, que sobrepuestos uno sobre de otro directamente extraídos del suelo y que, con la humedad propia de la zona, sus raíces siguen creciendo y se entrelazan unas con otras formando un muro sólido al cual no ingresa la humedad, frío o viento. La cubierta está constituida por un tijeral simple de ramas con cubierta de paja silvestre que se corta en una temporada del año específica para evitar que se descomponga por efectos de la humedad, lluvias, etc.

\section{Caso 03: Vivienda rural en el distrito de Ccapi, provincia de Paruro, departamento de Cusco}

Esta provincia es considera como la más pobre de la región Cusco, por ende, las expresiones arquitectónicas de vivienda vernácula se encuentran en estado de conservación deplorable y en muchos casos colapsadas; sin embargo, se puede apreciar algunos ejemplos de relación funcional del espacio central, donde predomina la distribución en planta, la relación visual del exterior al interior posee barreras arquitectónicas que buscan determinar el espacio de privacidad e intimidad.

Los materiales utilizados, así como las técnicas, provienen de legados de generación en generación, respetando costumbres como el wasitucucuy o fiesta del techado, donde los miembros de la comunidad ayudan al comunero en la techumbre de su vivienda, vinculando así a la sociedad por medio de su arquitectura. De igual forma, las técnicas constructivas, como el chaqlapeo, provienen de la tradición del empleo de la piel y lana de llama que sumergida en una mezcla de cal y agua es vertida con fuerza en el muro, dotándolo de color y textura representativa del lugar.

\section{Caso 04: Vivienda rural en el distrito de Ollantaytambo, provincia de Urubamba, departamento de Cusco}

Este caso particular merece especial atención porque es la mejor muestra del sincretismo religioso y cultural volcado en una edificación, ya que se encuentra en el distrito de Ollantaytambo, conocida como la ciudad de piedra viviente, en donde no se destruyó la trama urbana inca, sino por el contrario sirvió como cimiento para la edificación de las viviendas coloniales. De este modo, en la actualidad se pueden apreciar viviendas en uso parcial, donde se resalta la trama antes mencionada, conformando muros de Pirka a lo largo de su trazado urbano.

Es característico el empleo de recubrimientos en los muros de adobe y la exposición natural de mampostería de piedra, colaborando con el paisaje urbano de su entorno, permitiendo dibujar calles y vías que se pierden en el tiempo. Está demás mencionar que la ocupabilidad de estos recintos se debe en gran medida a la funcionalidad turística que poseen por los restos arqueológicos tan conocidos. Estas viviendas también comparten otros usos, como las adecuaciones que se vienen realizando con el objetivo de brindar servicios de hospedaje como hostales y hospedajes.

\section{DISCUSIÓN Y CONCLUSIONES}

De los antecedentes investigativos revisados, podemos inferir:

Que la arquitectura vernacular se compone de aspectos comunes sin que lleguen a ser tipologías estrictas, estas son: el entorno inmediato, uso de materiales autóctonos, el clima, las técnicas constructivas tradicionales y funcionalmente la presencia del espacio central, así como las cubiertas de dos aguas. 
El entorno, entendido no como el medio que rodea a la vivienda, sino como la extensión de la vivienda en su contexto, o la adopción de dicha vivienda en ese entorno establecido en el tiempo.

Uso de materiales de la zona como elementos fundamentales en el proceso de diseño y construcción de la vivienda vernácula, no referido al estatus social por lo económico o precario que pueda resultar la edificación, sino por la proximidad y capacidad de solución de problemas primarios, como resguardo a los factores climatológicos, la seguridad de las pertenencias y el cuidado de los animales.

Técnicas constructivas heredadas de generación en generación sin mayor conocimiento especializado, con soluciones improvisadas y propias de las necesidades temporales.

El clima como factor determinante, ya que es el primer problema o ventaja a tomar en cuenta al momento de la planificación y construcción de la vivienda vernácula, tales como temperatura, lluvia, horas de sol, humedad y viento. Estos elementos terminan por ser condicionantes que obligan a tomar decisiones sobre el uso del material, la orientación de los espacios y los sistemas de cubiertas.

El factor cultural, ya que por la evidencia recogida en los distritos de Cusco, en todas las viviendas analizadas y en las entrevistas a sus ocupantes, se observa que las técnicas constructivas, así como los ritos y tradiciones empleados en el diseño y edificación, proceden de la herencia oral de los ancestros, a los que se van incluyendo materiales contemporáneos sin que se pierda la esencia y el espíritu del lugar.

La arquitectura vernácula cusqueña se caracteriza en gran medida por cubiertas inclinadas de paja o teja de arcilla cocida soportadas por tijerales en sistema de par y nudillo o troncos de ramas amarradas con sogas de ichu. Los muros poseen secciones amplias para conservar el calor interior; sus cimentaciones no son profundas y son proyecciones en material y dimensiones de los muros superiores.

La relación funcional que ocurre entre los espacios no es lineal, sino que se dan por aglomeración, según su topografía, área del terreno, número de habitantes y actividad económica que ocupa a sus habitantes.

Su técnica constructiva responde a soluciones de necesidades específicas y a los materiales con los que se cuenta a su alrededor.

La autoría y dirección en la construcción de estas viviendas vernáculas se caracteriza por el conocimiento empírico de sus habitantes o personas que aprendieron el oficio de generación en generación, con lo cual se convierte en identidad cultural de cada zona analizada.

\section{REFERENCIAS}

CIAV-ICOMOS. (1993). Carta de la Arquitectura Vernácula. VIVIENDA, 68.

Araoz, I. (1995). Nuevos modelos en el crespúsculo de la arquitectura vernácula. Española.

Cárdenas, E. (2009). Identidad y Cultura. Conferencia presentada en el I Coloquio Nacional por la arquitectura Cubana Carnaguey. Cuba: Universidad de Cuba.

Carranza, M. (2010). ¿Existen técnicas adecuadas de construcción con tierra para países sísmicos? Barcelona: Universidad UPC Universitat Politécnica de Cataluña

Chaos, M. T. (2015). La Arquitectura vernácula como importante manifestación de la cultura. Arquitecturas del Sur, 63-73.

Estrada, T. (2005). Arquitectura vernácula $e$ identidad arquitectónica en una ciudad fronteriza. $76^{\circ}$ Asamblea Nacional de Asinea, 7.

Galindo, M. (2013). La Arquitectura vernácula, patrimonio de la humanidad. Biblioteca Virtual Miguel de Cervantes. 
García, G., Tamayo, J., \& Cobo, D. (2018). Estudio tipológico de la arquitectura vernácula. Aportes y síntesis de la complejidad. Arte y Sociedad, 296.

Gómez, J. (2010). Vivienda Efímera urbana, ¿Arquitectura vernácula? Bogota: Universidad de los Andes.

Guerrero, L. (2010). La herencia de la arquitectura tradicional. Alarife, 10-28.

ICOMOS. (1999). Carta del Patrimonio Vernáculo Construido. Ciudad de México: $12^{\circ}$ asamblea General en México.

Jimenez, A. (2006). El viaje de vuelta, el encuentro de la contemporaneidad a través de lo vernáculo. Granada: Universidad de Granada.

King, L. (s/f). La arquitectura vernácula del Noreste de México. Monterrey: Ediciones Universidad de Monterrey.

Landa, V., \& Segura, R. (2017). Algunas reflexiones sobre la "arquitectura vernácula". Cuadernas de Arquitectura, 68.

Navarrete, M., Vásquez, M., Castillo, A., \& Hernandez, A. (2018). Vivienda Vernácula en la sierra norte del estado de Puebla. Revista de Arquitectura y Diseño, 1-8.
Neila, J. (2015). Sostenibilidad y arquitectura. Conferencia académica presentada en la Escuela Técnica Superior de Arquitectura de Madrid. Madrid: Escuela Técnica Superior de Arquitectura de Madrid.

Paniagua, D. (s/f). Interpretación bioclimática de la arquitectura vernácula.

Peñaranda, L. (2011). Conservando nuestro patrimonio. Manual para la conservación del patrimonio arquitectónico habitacional de Sucre. Sucre: Universidad Politécnica de Catalunya.

Rapoport, A. (1972). Vivienday Cultura. Barcelona.

Scaletti, A. (2014). Arquitectura Vernácula residencial en Lamas, Perú: Un estudio tipológico. Lamas.

Sepúlveda, L. (2002). Al rescate de la arquitectura vernácula. Gaceta Universitaria, 14-15.

Tilleria, J. (2010). La arquitectura, sin arquitectos, algunas reflexiones sobre arquitectura vernácula. AUS.

Vasquez, M., Navarrete, M., \& Castillo, A. (2018). Causas de la desaparición de la vivienda vernácula en Tochimilco, Puebla . ECORFAN -Spain Journal, 30-40. 


\section{Apéndice A}

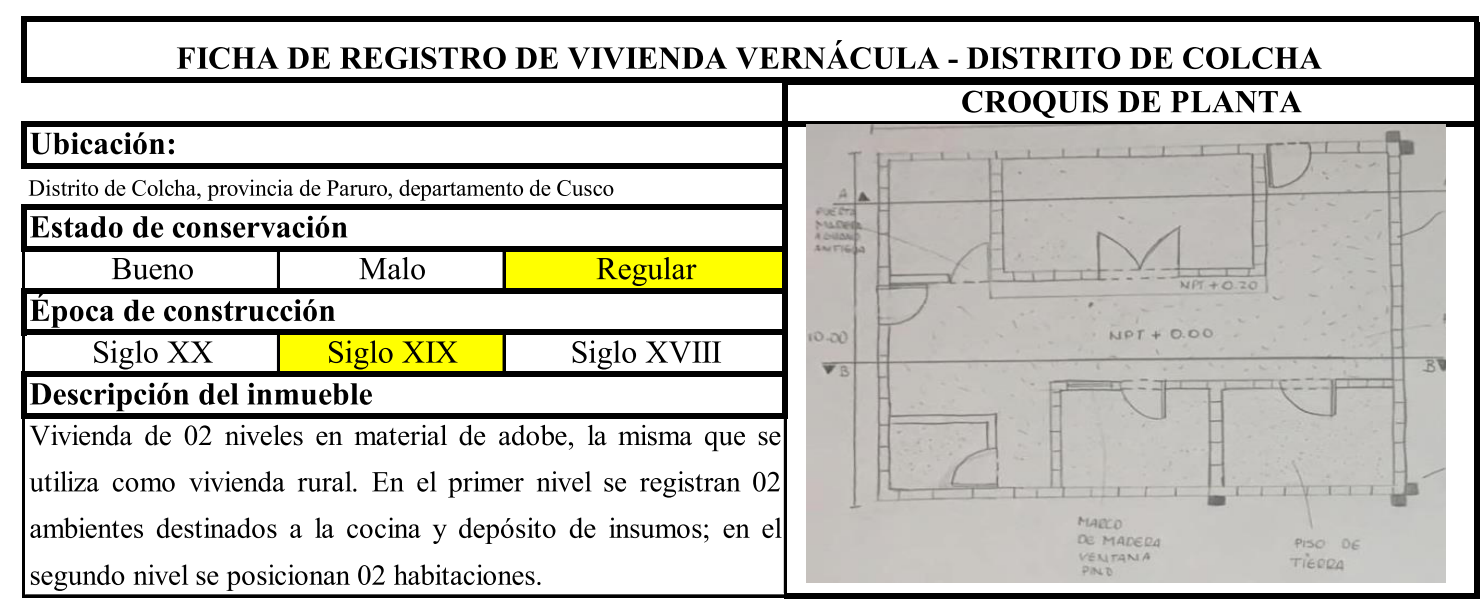

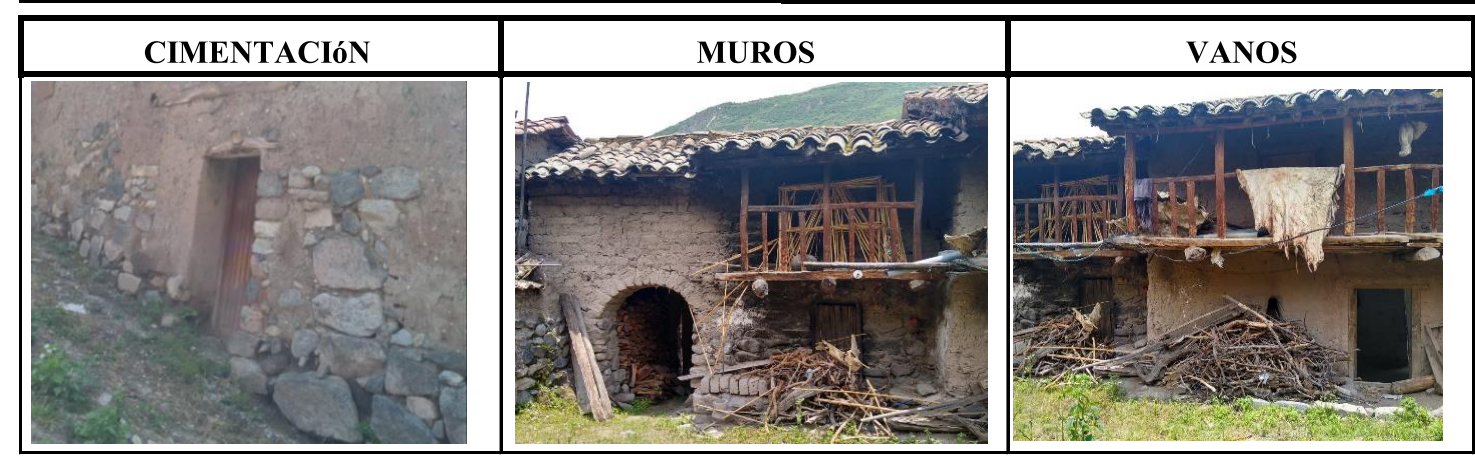

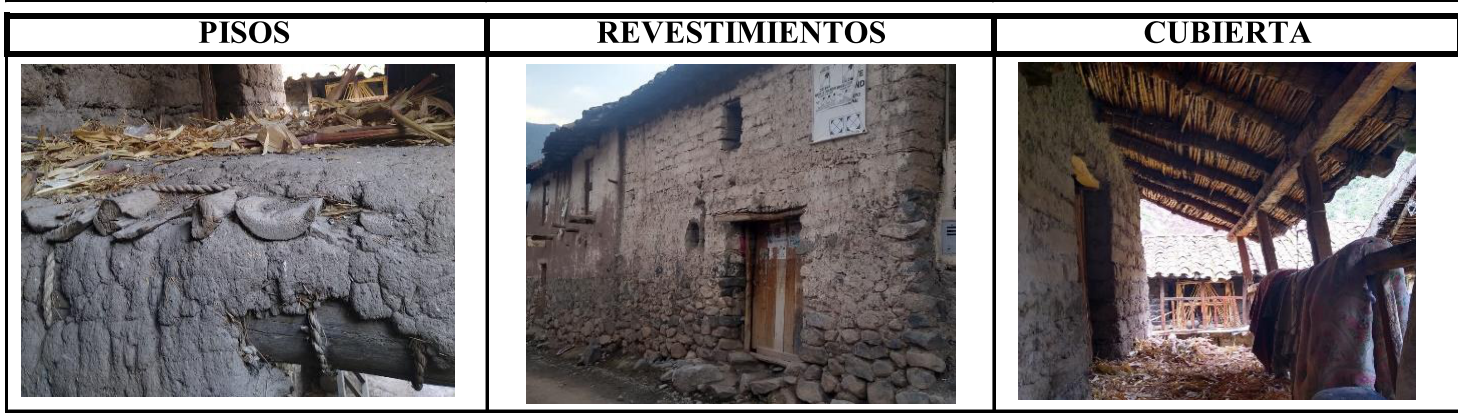

\begin{tabular}{|l|l|l|r|r|c|}
\hline \multicolumn{2}{|c|}{ TIPLOGIA FORMAL } & \multicolumn{2}{c|}{ TIPOLOGÍA FUNCIONAL } & \multicolumn{2}{c|}{ FíSICO CONSTRUCTIVA } \\
\hline Monumental civil & & Vivienda & & Cimentación & Piedra regular y barro \\
\hline Monumental religiosa & & Culto & & Muros & Adobe \\
\hline Arquitectura civil & & Educación & & Vanos & Madera de eucalipto \\
\hline Religiosa & Comercio & & Pisos & Tierra sobre enchaclado \\
\hline Vivienda Urbana & & Servicios & & Escalera & Piedra y barro \\
\hline Vivienda Rural & & Salud & & Cubierta & Par y nudillo/teja \\
\hline Arquitectura agrícola & & Productiva & & & \\
\hline
\end{tabular}

ANÁLISIS FUNCIONAL

La vivienda se encuentra dentro del sector urbano del distrito de Colcha. De su distribución se puede analizar el zaguán de ingreso con arquería de medio punto en adobe, así como el espacio central propio de la arquitectura colonial. Sin embargo, la factura del inmueble evidencia el empleo de mano de obra no calificada, además de elementos como la escalera de piedra y barro, el piso y entrepiso de tierra sobre enchaclado de carrizo y barro, que evidencian técnicas constructivas tradicionales, pero que no conllevan controles de calidad técnicos. En la actualidad, la vivienda se encuentra en uso como almacén de granos en el primer nivel y como vivienda en el segundo. El patio central posee la función original no solo como espacio de distribución, sino también como núcleo funcional donde se realizan actividades económicas, sociales y laborales. 
Vivienda vernácula de las provincias de Cusco

Julio-diciembre 2020

\section{Apéndice B}

FICHA DE REGISTRO DE VIVIENDA VERNÁCULA - DISTRITO DE OCONGATE

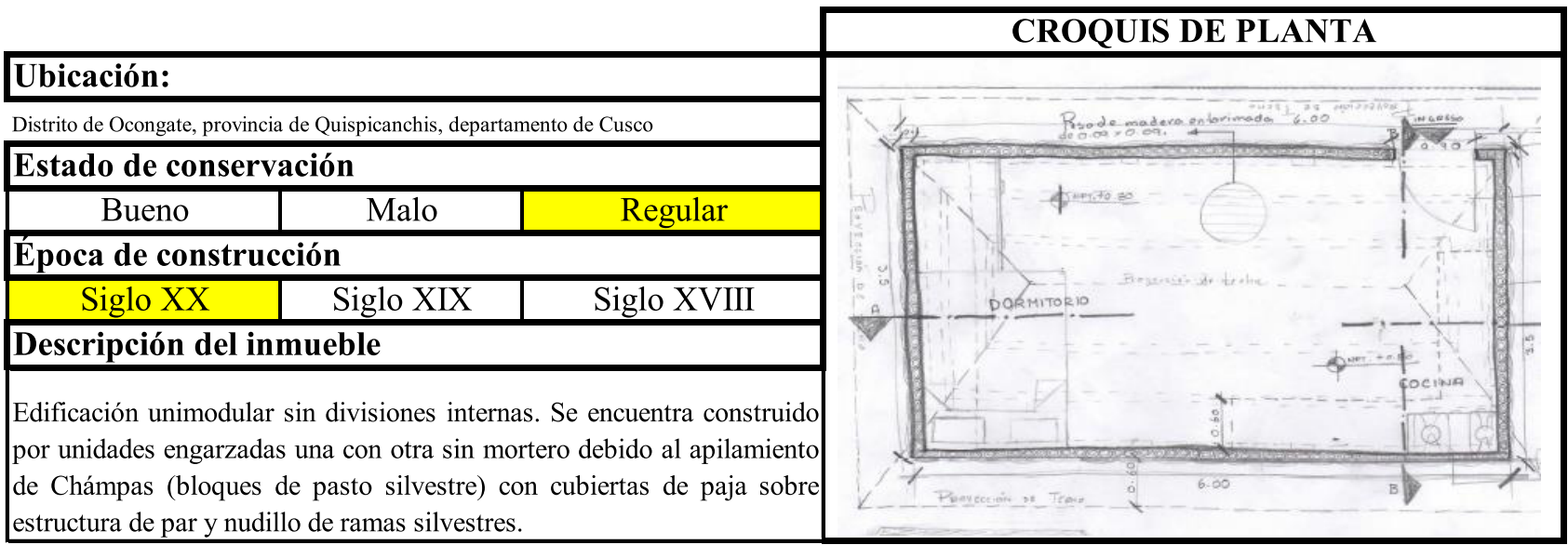

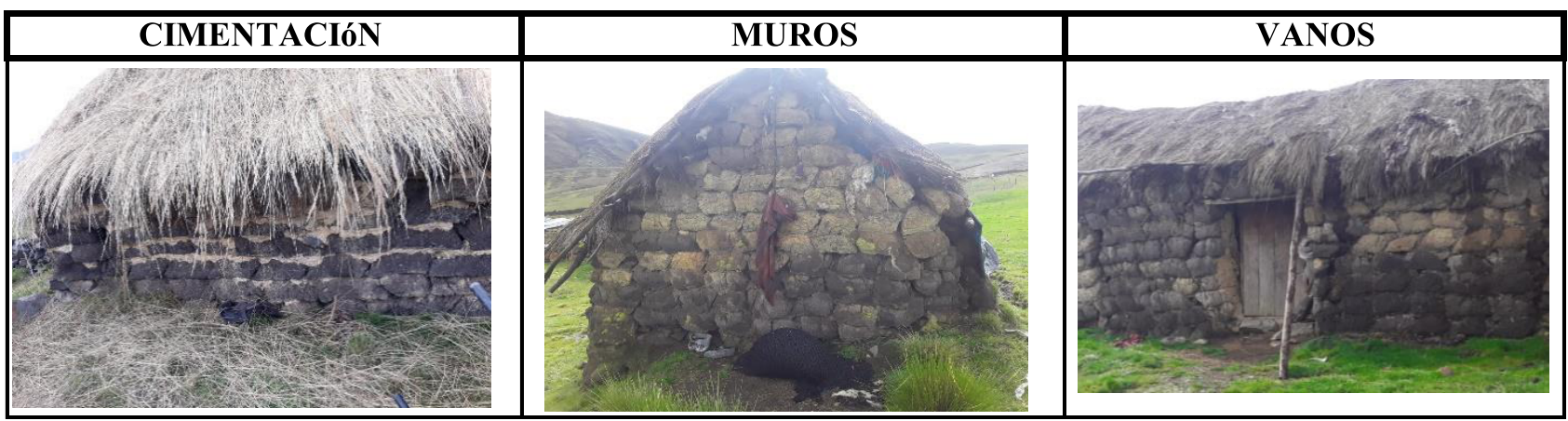

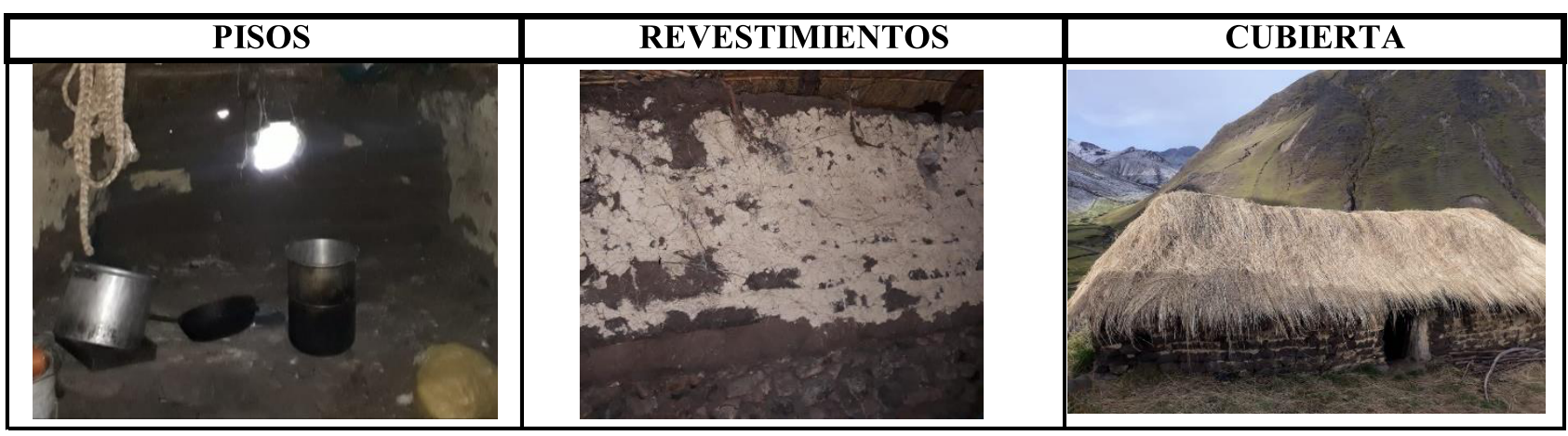

ANÁLISIS FUNCIONAL

La vivienda rural se caracteriza por no poseer barreras físicas que delimiten los predios, diferente a la urbe. Sin embargo, se encuentran elementos virtuales como árboles, lomadas y cercos vivos que evidencian la magnitud del área de influencia. Además que, si bien es cierto no cuenta con un espacio central definido, se aprecia un área donde se cumplen funciones comerciales como la venta de animales menores o ganado, así como actividades sociales y culturales como fiestas patronales, debido a que su ubicación se encuentra camino al santuario del Señor de Qoylloriti, una de las principales fiestas costumbristas de la región. 


\section{Apéndice C}

\section{FICHA DE REGISTRO DE VIVIENDA VERNÁCULA - DISTRITO DE CCAPI}

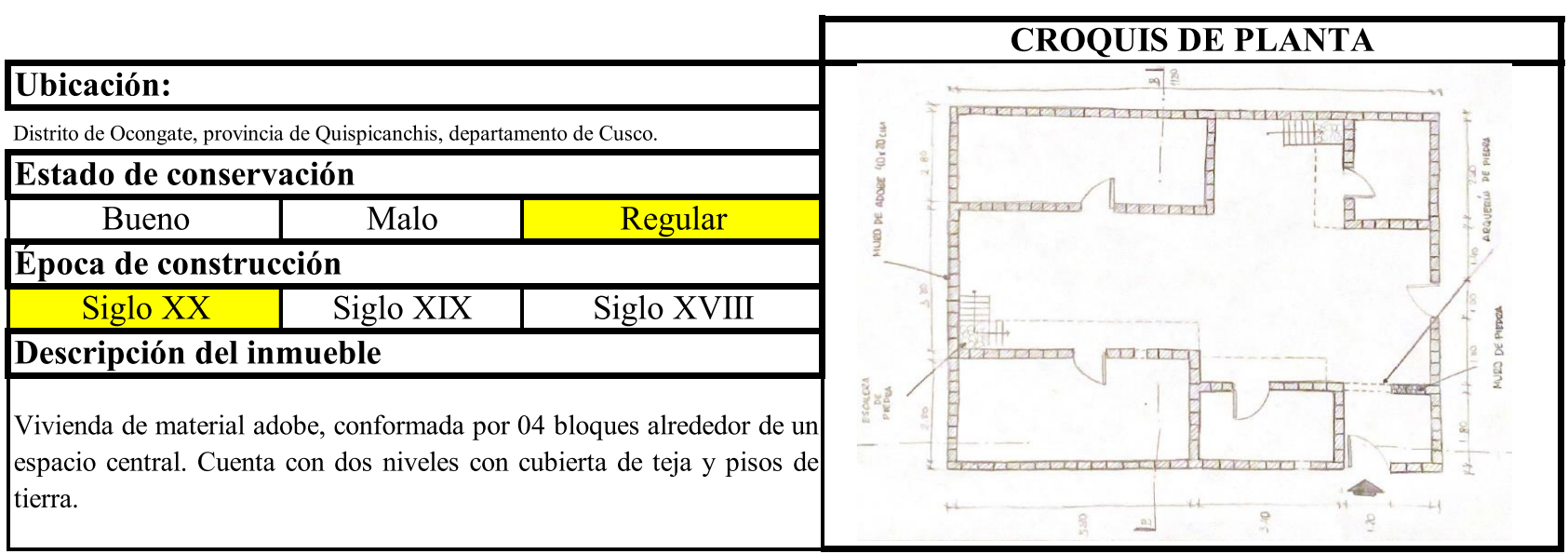
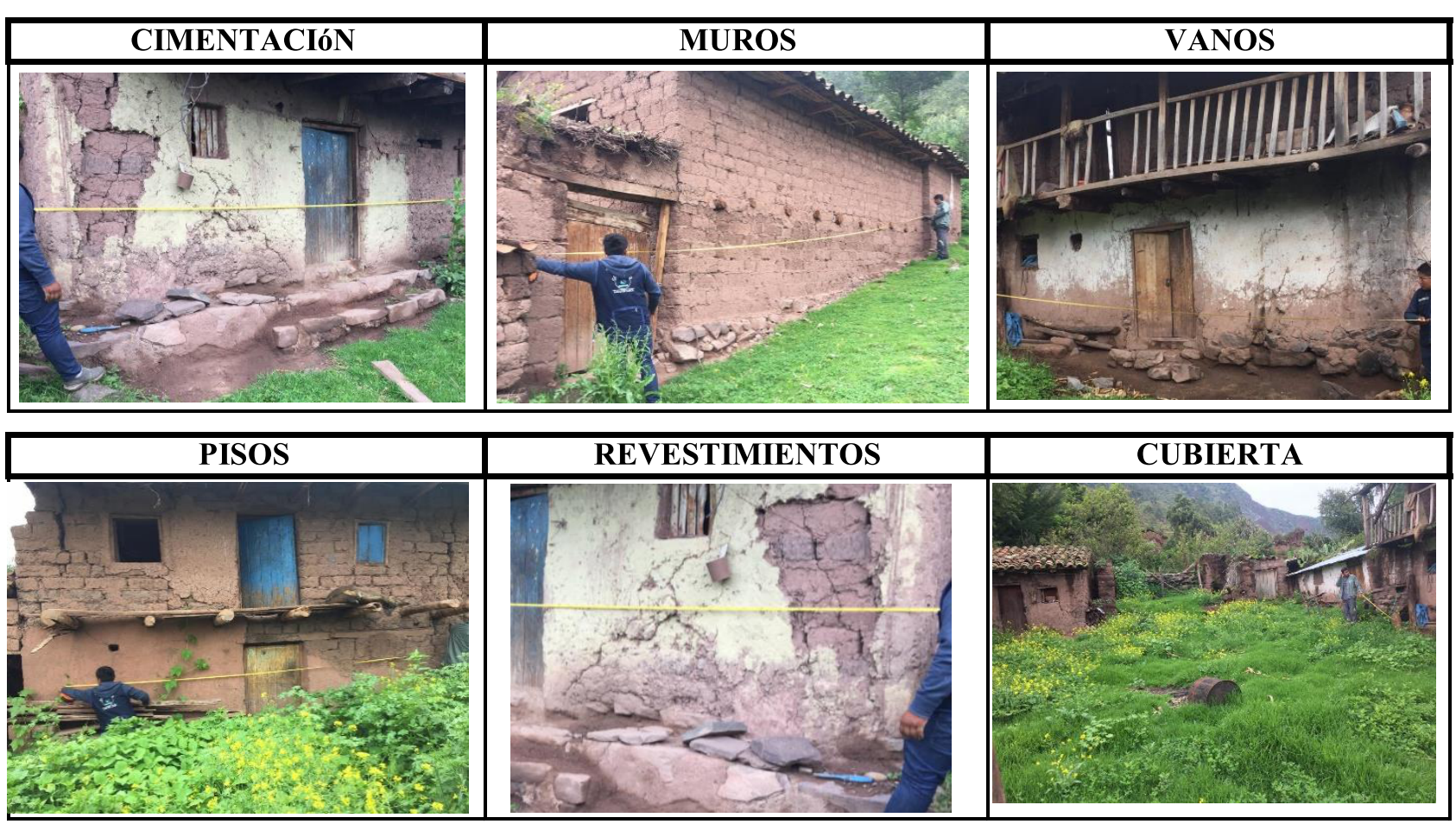

ANALISIS FUNCIONAL

Al igual que anteriores casos, la edificación se emplaza a través de un espacio central distribuidor, donde se desarrollan diferentes tipos de actividades. Por lo cual, a pesar de no ser un espacio arquitectónicamente definido, la función que desempeña le otorga el valor característico de la vivienda vernácula cusqueña. Es el espacio comunicador entre los diferentes bloques conformantes de la vivienda, en el que se cumplen funciones diferenciadas, como vivienda, almacén, espacio de animales menores y área de cocina. 
Vivienda vernácula de las provincias de Cusco

Julio-diciembre 2020

\section{Apéndice D}

\section{FICHA DE REGISTRO DE VIVIENDA VERNÁCULA - DISTRITO DE CCAPI}

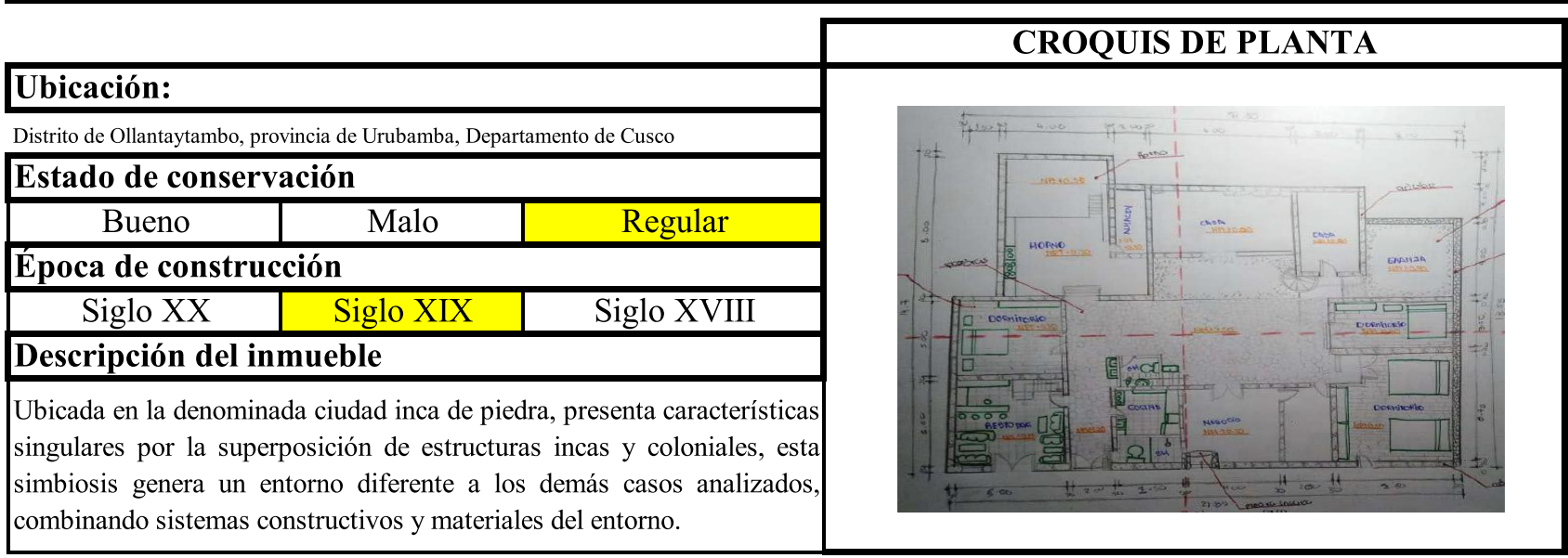

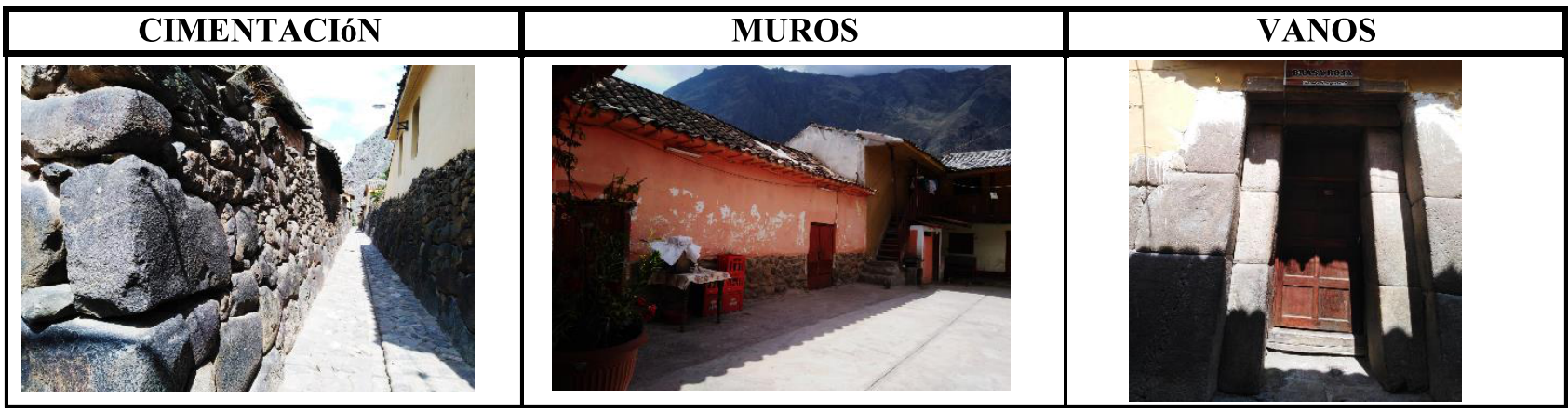

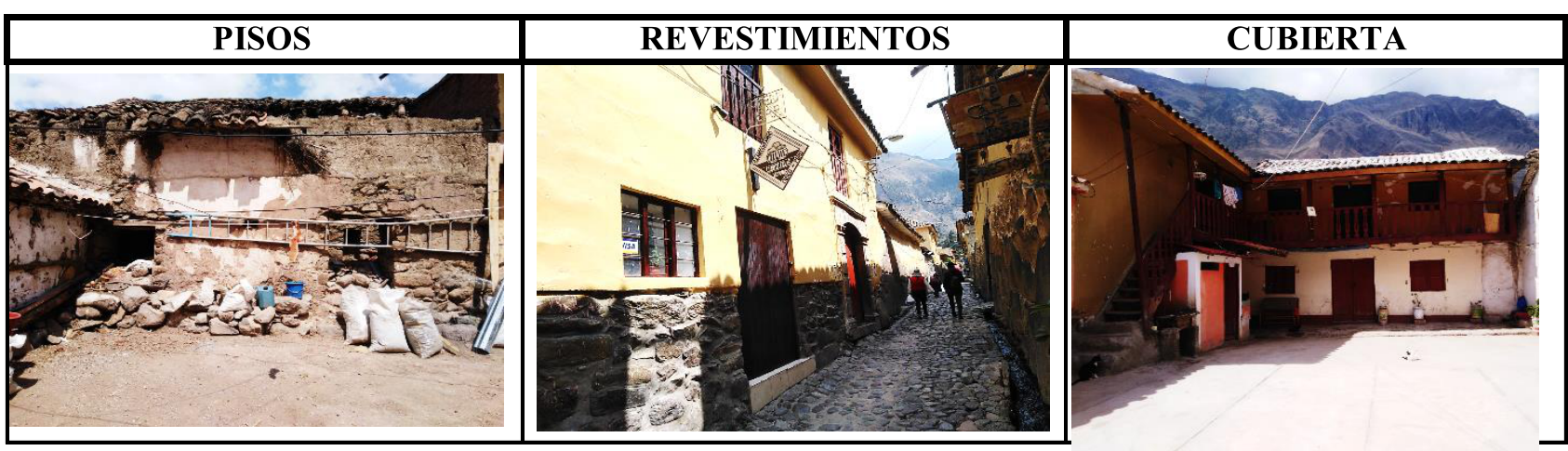

\section{ANÁLISIS FUNCIONAL}

Se circunscribe alrededor del patio central delimitando la manzana urbana. El estado de conservación no permite observar la edificación en su extensión original; sin embargo, como las típicas casas coloniales, posee muros de adobe que se levantan sobre muros y cimientos incas, respetando y adecuándose en su distribución interna espacial. La accesibilidad vertical se da por escaleras exteriores a los ambientes y enfrentados al patio donde se realizan actividades sociales, culturales y económicas vinculadas al turismo. 


\section{Apéndice E}

\begin{tabular}{|c|c|c|c|}
\hline \multicolumn{4}{|c|}{ FICHA DE REGISTRO DE VIVIENDA VERNÁCULA - DISTRITO DE MARANURA } \\
\hline & & & CROQUIS DE PLANTA \\
\hline \multicolumn{3}{|l|}{ Ubicación: } & \\
\hline \multicolumn{3}{|c|}{ Distrito de Maranura, provincia de La Convención, departamento de Cusco } & \\
\hline \multicolumn{3}{|c|}{ Estado de conservación } & \\
\hline Bueno & Malo & Regular & i \\
\hline \multicolumn{3}{|c|}{ Epoca de construcción } & \\
\hline Siglo XX & Siglo XIX & Siglo XVIII & \\
\hline \multicolumn{3}{|c|}{ Descripción del inmueble } & \\
\hline \multicolumn{3}{|c|}{$\begin{array}{l}\text { Bloque de } 02 \text { niveles con cimientos de piedra y barro, muros de adobe, } \\
\text { vanos de madera tornillo y cubiertas con tijeral de madera sin cielo raso. }\end{array}$} & \\
\hline
\end{tabular}

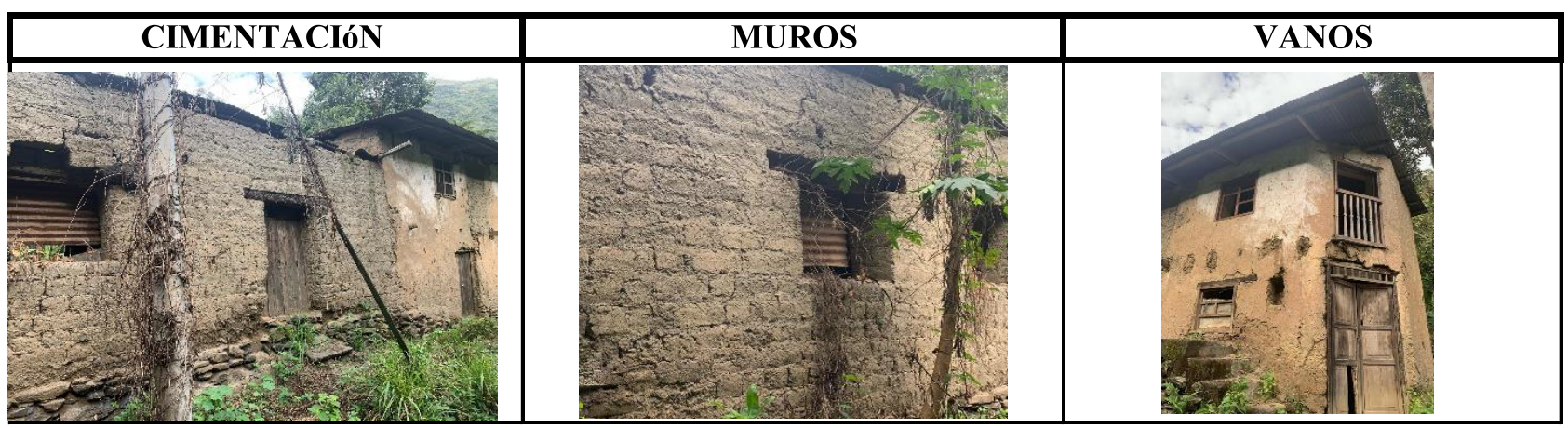

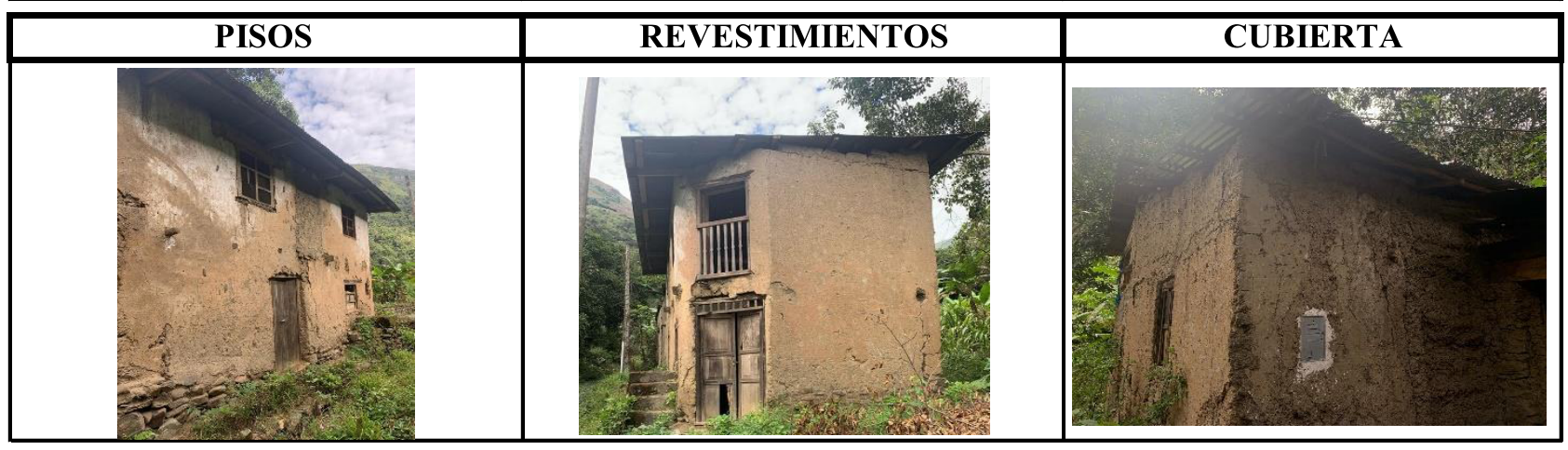

ANÁLISIS FUNCIONAL

Se caracteriza por tener bloques unidimensionales de muros de adobe con revestimientos de embarre de tierra y arcilla. El primer nivel está conformado por el espacio de trabajo (almacenes de frutas, equipos); en el segundo nivel se distribuyen los dormitorios o espacios íntimos. Por ser vivienda agraria, se da prioridad a los espacios de almacenaje; y debido al clima cálido de ceja de selva, los ambientes poseen alturas mayores a los demás casos analizados, así como el empleo de cubiertas de planchas de zinc para disipar el calor interior. 